\title{
AC 2007-2269: ASSESSING IMPACT OF OUTREACH ACTIVITY ON MOTIVATION OF UNDERGRADUATE ENGINEERING STUDENTS
}

\section{Deborah Switzer, Clemson University}

Dr. Debi Switzer is a Professor of Teacher Education at Clemson University. She teaches educational psychology courses, including learning and motivation theory, measurement, and research methods. She spent the first nine years of her career as a secondary mathematics and computer science teacher. She has been at Clemson University since 1989. In 2000 Dr. Switzer was named a Governer's Distinguished Professor by the S.C. Commission on Higher Education, and she received the Award for Faculty Excellence from the Clemson Board of Trustees in 2001. In 2003 she received both the Outstanding Faculty Member in Teaching Award from the Eugene T. Moore School of Education, and the Prince Award for Innovation in Teaching presented by the Clemson University Student Government. In 2005 she was named the Eugene T. Moore School of Education Outstanding Faculty Member in Service. She has given teaching effectiveness workshops at new faculty orientation for over a decade. Dr. Switzer is serving in her third term as a consulting editor for the Journal of Educational Research. In research projects she has collaborated with faculty in engineering, psychology, education, recreation, counseling, public health, and business, supplying expertise in assessment and experimental design. In 2000, she received the Harold E. Mitzel Award for Meritorious Contribution to Educational Practice Through Research. With Chemical Engineering faculty she was funded through NSF to develop assessment instruments and experimental design for research into a new model for educating engineering students. Her interests in assessment and research design have broadened to include electronic portfolios used in student assessment and program evaluation.

\section{Lisa Benson, Clemson University}

Dr. Lisa Benson is an Assistant Professor in the Department of Engineering and Science Education, with a joint appointment in the Department of Bioengineering, at Clemson University. Her research areas include engineering education and musculoskeletal biomechanics. Education research includes the use of active learning in undergraduate engineering courses, undergraduate research experiences, and service learning in engineering and science education. Biomechanics research includes the development of a novel system of inertial sensors to evaluate kinetics and kinematics of the lower limb, for use in determining physiological loading patterns and biomechanics education. She is a member of the American Society of Mechanical Engineers, American Society for Engineering Education, Sigma Xi, Orthopaedic Research Society, Society for Biomaterials, and Tau Beta Pi. Her education includes a B.S. in Bioengineering from the University of Vermont, and M.S. and Ph.D. degrees in Bioengineering from Clemson University. 


\section{Assessing Impact of Outreach Activity on Motivation of Undergraduate Engineering Students}

\section{Introduction}

This study was conducted to investigate how participation in conducting pre-college outreach activities impacts the retention of freshman engineering students. A design project in a freshman engineering class engaged students in creating physical models and activities to demonstrate math, physics or chemistry concepts to high school students. The focus of this paper is on the survey that was developed and implemented to study the impact of this activity on the students' motivation to remain in the engineering program.

\section{VIE Theory}

Retention of students in an academic program is fundamentally the issue of motivation to participate in the program. When a student loses his motivation in this situation, he will likely change majors or drop out. A program needs to be aware of the potential problems that could result in lowered motivation to remain in the program. A useful theoretical basis for identifying problem areas and determining effective interventions is VIE motivation theory.

VIE theory ${ }^{1}$ conceptualizes motivation as the interaction of three elements: Valence, Instrumentality, and Expectancy. The motivation to perform a behavior (like participating in an engineering program) depends on the goals set by the person-those goals that will eventually be reached if the behavior is successfully performed. The first step in understanding motivation is to identify these goals. Then the motivation to perform the behavior can be analyzed through the three VIE elements.

Valance $(\mathrm{V})$ is the value we get from a behavior. Valance can come from the behavior itself (it is fun to do), or it can come from the value of the goals associated with the behavior. Valance is additive - the more goals (or outcomes) associated with the behavior, the more value added. The higher the valence, the greater the motivation will be. For example, a researcher may place a high value on writing a book, because, although it may not be an especially enjoyable pastime, one of the goals of writing the book, promotion, has high value. One way to increase the valance of writing the book is to make the behavior more fun (choosing a topic that is a personal passion, or joining a writing society) or to add more goals (personal rewards after each chapter, for example). Each additional, valued goal adds valance to the behavior, increasing motivation to perform the behavior.

Instrumentality (I) is the perceived connection between the behavior and the goals. For motivation to exist, the person must believe that performing the behavior will result in progress toward achieving the goals. This is an element of motivation that is ignored by many motivation theories. Yet it is a necessary part of the motivation equation. For example, if the researcher writing the book finds out that the field is currently glutted with books, and that publishers are not interested in new books at this time, she will have low instrumentality-she will perceive the probability of publishing as very low, and therefore her motivation to write the book will be low. To increase her motivation, she will have to find a publisher who will commit to the book. If the 
researcher could get a contract for the book, instrumentality would be very high, and motivation potentially would be high.

Expectancy (E) is the perceived probability that the behavior can be successfully performed. To have motivation, the person must believe that all the knowledge, skills, and resources necessary for the behavior are present. The researcher would have to believe that she knows (or can find) all the information needed for the book, that she has the ability to manage her time, that she has a working computer with a familiar word processor and enough storage capacity for the book, as well as a scanner, internet access, or other technology needed for the writing to go smoothly. To increase her expectancy, she might interview someone who has successfully written a book to see what software and hardware that person used, or she might sketch out a concept map of the book to make sure she has a solid understanding of the content she will need to include. The higher her expectation that she can successfully write the book, the higher her motivation will be.

According to VIE Theory, all three elements must be present for motivation to exist. For a person to want to perform a behavior, the behavior must be associated with one or more goals, and there must be some expected valance (value coming from the behavior itself and/or one or more of the goals), and there must be instrumentality (belief that the behavior does contribute to the progress toward the goals), and there must be expectancy (belief that the behavior is within the capability of the individual). If any one of these elements is zero, motivation will be zero. To increase motivation, one must try to guarantee that none of the elements are zero, or even near zero. Additionally, it is important to realize that increasing any ONE of the elements will result in increased motivation. VIE Theory has been used as a theoretical base for motivational planning in industry and business ${ }^{2}$.

\section{Context: Outreach Activity}

Freshman engineering students typically participate in a design course during their second semester. During the Spring 2006 semester, these students were assigned a design challenge to create active learning tools for middle and high school students that demonstrate a concept, process or technology in science, physics, engineering, or math. Three hundred students enrolled in "Engineering Fundamentals" were assigned to teams of three to four, and completed the design process through the following steps. Student teams designed a physical model, active learning tool or demonstration, and developed written and oral support materials. Student teams presented their design projects to the instructors and $4-5$ other teams. The students' attitude toward their engineering program was assessed both before and after the design challenge with an instrument created for this project based on VIE Theory. The study protocol was approved by the Institutional Review Board prior to the start of the study. 

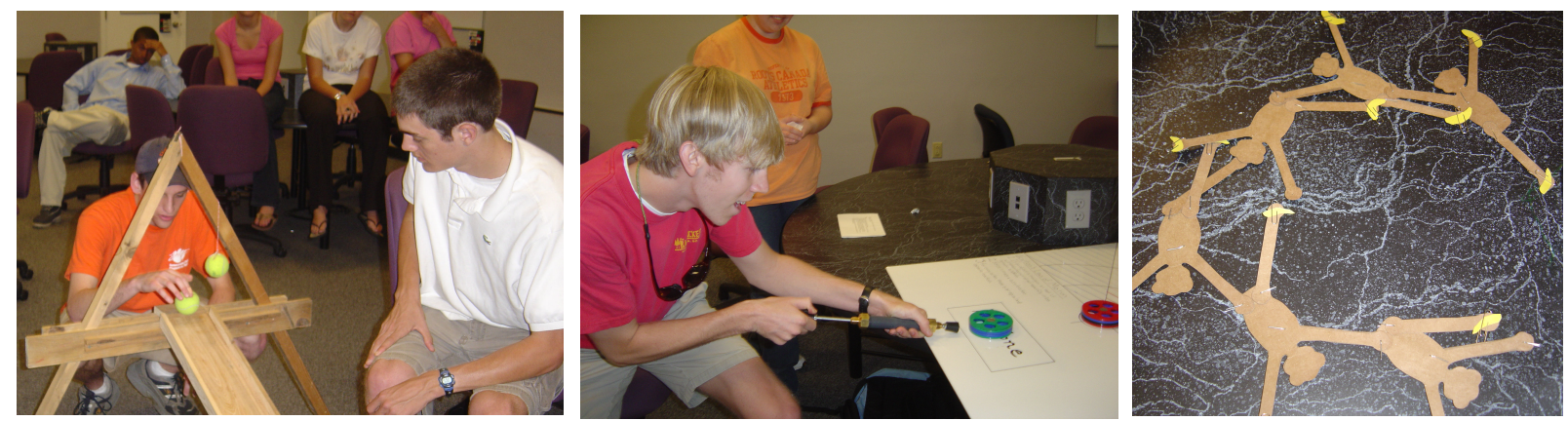

Figure 1, from left to right: Engineering students demonstrating a physical model of the conservation of energy, an interactive game using Newton's Laws of Motion, and a model of polymer "monkey" chains.

The Attitude Survey

Construction of the survey

To measure the motivation of undergraduate engineering students to remain in the program before and after the design project, a survey was developed based on the VIE (Valence, Instrumentality, and Expectancy) theory of motivation ${ }^{1}$. The survey was designed to assess motivation to remain in an engineering discipline (the "behavior"), with the understanding that this behavior leads to the goal of entering the engineering profession. Content of items was based primarily on the ABET standards for undergraduate programs in engineering.

The survey measured four constructs: value of participating in the coursework/program, value of being an engineer, instrumentality of the coursework for attaining a career in engineering, and expectancy of success in the coursework/program. The survey originally consisted of 45 items with a Likert scale (strongly disagree, disagree, neutral, agree, or strongly agree). Each VIE construct (valence, perceived instrumentality, and perceived expectancy) was assessed. The instrument was analyzed for reliability (Coefficient alpha) as a whole, and within each construct (correlation of each item with its construct). Items with low item-construct correlations (below 0.40) were removed one at a time (lowest correlation first), and the effect on the construct reliability was observed. If the reliability went up appreciably, the item was removed permanently. This process continued until a final reliability was reached for each construct. One item was included in the survey twice to check the reliability of student answers.

\section{Valance}

Valance items measured how much the students valued participating in their current coursework (behavior) as well as the value they placed on becoming an engineer (goal). Initially there were eight items assessing value of the behavior. Item/construct correlations for these items ranged from 0.65 to 0.48 , with the overall construct reliability, as estimated by Coefficient alpha equal to 0.747 . No items were removed.

Item/construct correlations of the seven items measuring value of the goal ranged from 0.39 to 0.71 , with reliability of 0.6674 . One item ("My family is encouraging me to be an engineer.") had the least relationship to the overall construct (correlation of 0.39), and when 
removed, the construct reliability increased to 0.686 , so that item was permanently removed from the survey.

Instrumentality

Eleven instrumentality items assessed how certain the students were that successful participation in the engineering program would result in becoming a practicing engineer. Item/construct correlations ranged from 0.44 to 0.59 , with an overall construct reliability of 0.723 . One item within this construct was repeated, to check that students were answering the items reliably. The two occurrences of this item had an inter-correlation of 0.87 . Since this is a strong correlation, and evidence that students were consistently answering the items, one occurrence of the repeated item was permanently removed from the survey.

Expectancy

Expectancy items measured how certain the students were that they could successfully perform the requirements of the program coursework. Initially the construct reliability for these nineteen items was 0.785 , and there were several items with low item/construct correlations. Removing each, one at a time, and recalculating the reliability identified only three items that needed to be removed from the survey to increase the construct reliability:

- I can write effectively. (0.30)

- I spend less time on homework than my friends in other majors. (0.17)

- The engineering major is one of the hardest. (0.21)

With the permanent removal of these three items from the survey, the expectancy construct reliability increased to 0.815 .

In summary, the resulting survey with its 40 items had a reliability (Coefficient alpha) of 0.883. The value of participation in the program (behavior value), measured with eight items, has a reliability of 0.747 . The six items assessing the value of becoming an engineer (goal value) has a reliability of 0.686 . The connection between program participation and entering the engineering profession (instrumentality) is measured with ten items with reliability of 0.723 . The remaining 16 items assess student confidence of successful participation in the engineering program (expectancy), with a reliability of 0.815 .

The survey uses a Likert scale (strongly agree to strongly disagree), scored from +2 to -2 , so a score of 0 on an item represents neutral attitude. Some items are reversed scored $(-2$ to +2$)$ since they are negatively stated, and to agree with them is evidence of a negative attitude (see Appendix A). The survey produces four scores for each student: value of participation in the engineering program $(\mathrm{Vb})$, value of attaining a career as an engineer $(\mathrm{Vg})$, instrumentality of program participation for attaining an engineering career (I), and expectancy of success in participating in the program (E). Since valance is summative (all sources of value contribute to a total valance for the behavior), $\mathrm{Vb}$ and $\mathrm{Vg}$ are sums of their respective item scores. Since $\mathrm{Vb}$ is the sum of 8 items measuring value of the behavior (participation in the program), the possible range of scores is -16 to +16 , and any score above zero shows perceived value coming from being in an engineering program. $\mathrm{Vg}$ is the sum of six items, so the possible range of scores is 12 to +12 , with zero representing a neutral attitude. The I and E scores are calculated by averaging their respective items, since these constructs are probabilities and the items represent 
necessary conditions. Therefore the range of possible scores for both I and $\mathrm{E}$ is -2 to +2 , with zero representing a neutral attitude. Appendix A shows the mapping of items to constructs.

Results

The attitude survey was given to 160 students before and after the three week design project. Overall the group mean scores for valance ( $\mathrm{Vb}$ and $\mathrm{Vg}$ ), instrumentality (I), and expectancy (E) represented a positive attitude on both the pre- and post-survey (see Table 1). Analyzing the student responses using a multivariate repeated measures analysis of variance showed there was no significant change over time for any of the elements measured. (The within-subjects effect of time had the following values: $\mathrm{F}=2.143, \mathrm{df}=4, \mathrm{p}=0.078$.) The group means for the pre- and post-surveys can be seen in Table 1 .

Table 1: Group Means (s.d.) of Pre- and Post-Surveys

\begin{tabular}{|l|l|l|l|}
\hline Construct & $\begin{array}{l}\text { Pre-survey } \\
\text { Group Mean }\end{array}$ & $\begin{array}{l}\text { Post-survey } \\
\text { Group Mean }\end{array}$ & $\begin{array}{l}\text { Possible range } \\
\text { of scores }\end{array}$ \\
\hline Value of behavior (sum of items) & $6.02(3.68)$ & $6.00(4.11)$ & -16 to +16 \\
\hline Value of goal (sum of items) & $7.24(2.46)$ & $6.98(2.46)$ & -12 to +12 \\
\hline Instrumentality (mean of items) & $0.85(.36)$ & $0.89(.35)$ & -2 to +2 \\
\hline Expectancy (mean of items) & $0.72(.38)$ & $0.72(.36)$ & -2 to +2 \\
\hline
\end{tabular}

Analysis of the 160 individual students revealed two who had negative valences $(\mathrm{Vb}+\mathrm{Vg})$ that did not improve over time. Two students had negative expectancies, and one student had a consistently negative instrumentality. One other student had both negative valance and negative expectancy.

\section{Discussion}

The attrition of enrollments in engineering schools has attracted much attention from engineering educators in the past decade. Many engineering students can effectively absorb information and concepts within traditional classroom settings (lecture and individual work), but it has been recommended that a variety of teaching methods be used to accommodate different learning styles ${ }^{3}$, including active and cooperative learning.

Based on the survey results, there was no significant effect of activity on motivation from pre- to post- activity. However, the students only had three weeks to work on this project, and it is not realistic to expect a measurable change in that period of time. In future versions of this study, a longer period of time will be given for the students to study the concepts and develop ideas about how best to demonstrate them, thus giving more time for them to experience a change in valence, instrumentality and/or expectancy.

Although the results of this study indicated a generally positive motivation for the group, the survey results may be used to identify individuals who may be experiencing a lack of motivation to continue in the engineering program. Herein lies perhaps the most powerful and useful aspect of the survey for undergraduate engineering programs. By highlighting those persons with negative or zero construct scores, steps may be taken to intervene before the 
students change majors or drop out. It is important to point out that a zero/negative for valance, instrumentality, OR expectancy represents a potential problem with motivation to remain in the program, no matter how high the other constructs scores are. In addition, valance is additive, coming from either the value of the behavior or value of the goal. So as long as $\mathrm{Vb}+\mathrm{Vg}$ is positive, that student may not need an intervention to increase motivation to remain in the program. For example, one student in the study had a $\mathrm{Vb}$ score of -1 , but a $\mathrm{Vg}$ of 9 . Although he or she may not have been enjoying the coursework, the positive aspects of becoming an engineer should be enough to keep the student in the program. In contrast, another student had a $\mathrm{Vb}=-3$ and $\mathrm{ag}=1$. This student may not have placed enough value in becoming an engineering professional to overcome the negative experience he or she is having in the program. A student scored in the negative range in expectancy $(-0.13$ on the pre-test and -0.25 on the post-test) and evidenced a dropping valence (pre-test $\mathrm{Vb}=-3, \mathrm{Vg}=5$; post-test $\mathrm{Vb}=-5, \mathrm{Vg}=4$ ) for which his value of becoming an engineer $(\mathrm{Vg})$ may not be compensating enough for his negative attitude toward participation in the engineering program $(\mathrm{Vb})$. An analysis of the student's survey responses paints a picture of someone who is not getting any fun or satisfaction from coursework, and is feeling unprepared and unsuccessful. A study group, or other social network may alleviate some of this student's anxiety, help him make friends and increase enjoyment, and help him develop some useful strategies for dealing with the workload.

If the survey results indicate a negative (or zero) trend among students in a program, the construct scores can indicate the areas needing improvement. For example, if the group mean for the value of the goal is near zero, a program of guest speakers from a variety of engineering firms may help students see the value and potential satisfaction of the engineering profession. If instrumentality is low, the guest speakers should be graduates of a university's program, so they have a shared educational experience that can be directly connected to attaining a successful engineering career. Again, analysis of the specific items that are receiving low scores will inform decisions about appropriate programmatic interventions.

\section{Conclusions and Future Recommendations}

In future versions of this study, a longer period of time will be given for the students to study the concepts, to develop ideas about how best to demonstrate them, and to increase motivation through the increase of valance, instrumentality, and expectancy. Specific programmatic responses to evidence of low retention motivation will be documented and evaluated for effectiveness.

\footnotetext{
References

${ }^{1}$ V. H. Vroom, Work and motivation. New York: Wiley, 1964.

2 T.B. Green, Performance and motivation strategies for today's workforce: A guide to expectancy theory applications. London: Quorum Books, 1992.

${ }^{3}$ R. M. Felder, G.N. Felder and E. J Dietz, A longitudinal study of engineering student performance and retention. V. Conparisons with traditionally-taught students. Journal of Engineering Education, October 1998, pp. 469 - 480.

${ }^{4}$ D.C. Berliner and R.C. Calfee eds, Cognition and Learning, in Handbook of Educational Psychology. MacMillan Reference Books, 1996.
} 


\section{Appendix A: Mapping of Items to Constructs}

Value of the Behavior (Participation in Engineering Coursework)

How much do the students value the process of their coursework / program?

1. I am having fun in my major.

2. My overall attitude about my engineering department is positive.

6. I get satisfaction from my presentations in engineering classes.

7. I enjoy applying what I know in my classes.

10. My course work is important to my success.

17. I get satisfaction from my coursework.

20. I feel pride when I tell others that I am an engineering major.

27. I get satisfaction from my design projects.

Value of the Goal (Engineering Profession)

How much do the students value the engineering profession?

9. I appreciate the need for life-long learning.

12. I can see how engineering improves quality of life for our society.

13. Engineers are respected by society.

15. I want to be an engineer.

25. The field of engineering is interesting.

35. I am confident about my choice of major.

\section{Instrumentality}

How likely do the students feel that successful completion of coursework will lead to becoming an engineer?

5. I am committed to engaging in life-long learning.

8. I can use the techniques, skills, and modern engineering tools necessary for engineering practice.

21. My course work is preparing me for my first job.

14. I have an understanding of professional and ethical responsibility.

22. I have received the broad education necessary to understand the impact of engineering solutions in a global and societal context.

31. The university is preparing me well to become an engineer.

32. I can speak in front of an audience effectively.

37. I can apply my knowledge of mathematics, science, and engineering.

38. I can design a system, component, or process to meet desired needs.

39. I am dissatisfied with my educational progress. (reverse score)

\section{Expectancy}

How likely do the students feel they will be successful in their engineering coursework?

3. I can analyze and interpret data.

4. I can function on problem-solving teams.

11. I can identify, formulate, and solve engineering problems.

16. The course work in engineering classes is easy.

18. I am struggling with my college courses. (reverse score)

19. I am struggling with my engineering courses. (reverse score)

23. I am encouraged and supported in my studies by the engineering faculty.

24. I lack self-confidence. (reverse score)

26. I can think critically.

28. I am having to work harder than many of the other students in my classes. (reverse score)

29. My math courses have prepared me for this course.

30. I am considering switching majors. (reverse score)

33. I can design and conduct experiments.

34. My science courses have prepared me for this course.

36. I have developed a knowledge of contemporary issues through my engineering courses.

40. I am being exposed to new ideas in my engineering courses. 


\author{
Appendix B: The Attitude Survey \\ Attitude of Undergraduates Toward Their Engineering Program
}

\title{
Directions: \\ Indicate how strongly you agree or disagree with each of the following statements by circling the best representation of your opinion.
}

\section{SA=Strongly Agree $A=$ Agree $\quad \mathrm{N}=$ Neutral $\mathbf{D}=$ Disagree $\mathrm{SD}=$ Strongly Disagree}

1. I am having fun in my major.

2. My overall attitude about my engineering department is positive.

3. I can analyze and interpret data.

4. I can function on problem-solving teams.

5. I am committed to engaging in life-long learning.

6. I get satisfaction from my presentations in engineering classes.

7. I enjoy applying what I know in my classes.

8. I can use the techniques, skills, and modern engineering tools necessary for engineering practice.

9. I appreciate the need for life-long learning.

10. My course work is important to my success.

11. I can identify, formulate, and solve engineering problems.

12. I can see how engineering improves quality of life for our society.

13. Engineers are respected by society.

14. I have an understanding of professional and ethical responsibility.

15. I want to be an engineer.

16. The course work in engineering classes is easy.

17. I get satisfaction from my coursework.

18. I am struggling with my college courses.

19. I am struggling with my engineering courses.

20. I feel pride when I tell others that I am an engineering major.

21. My course work is preparing me for my first job.

22. I have received the broad education necessary to understand the impact of engineering solutions in a global and societal context.

23. I am encouraged and supported in my studies by the engineering faculty.

24. I lack self-confidence.

25. The field of engineering is interesting.

26. I can think critically.

27. I get satisfaction from my design projects.

28. I am having to work harder than many of the other students in my classes.

29. My math courses have prepared me for this course.

30. I am considering switching majors.

31. The university is preparing me well to become an engineer.

32. I can speak in front of an audience effectively.

33. I can design and conduct experiments.

34. My science courses have prepared me for this course.

35. I am confident about my choice of major.

36. I have developed a knowledge of contemporary issues through my engineering courses.

37. I can apply my knowledge of mathematics, science, and engineering.

38. I can design a system, component, or process to meet desired needs.

39. I am dissatisfied with my educational progress.

40. I am being exposed to new ideas in my engineering courses.
SA A $\quad$ N $\quad$ D $\quad$ SD

SA A $\quad$ N D $\quad$ SD

SA A $\quad$ N $\quad$ D $\quad$ SD

SA A $\quad$ N $\quad$ D $\quad$ SD

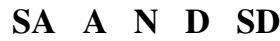

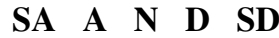

SA A N D SD

SA A $\quad$ N $\quad$ D $\quad$ SD

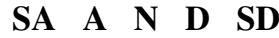

SA A N D SD

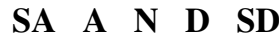

SA A $\quad$ N D SD

SA A N D SD

SA A N D SD

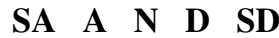

SA A N $\quad$ D $\quad$ SD

SA A N D SD

SA A $\quad \mathbf{N}$ D $\quad$ SD

SA A $\quad \mathbf{N}$ D SD

SA A N D SD

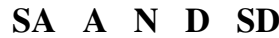

$\begin{array}{lllll}\text { SA } & A & \mathbf{N} & \mathbf{D} & \text { SD }\end{array}$

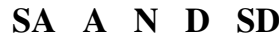

SA A N D SD

SA A N D SD

SA A N D SD

SA A $\quad$ N $\quad$ D SD

SA A N $\quad$ D SD

SA A N $\quad$ D $\quad$ SD

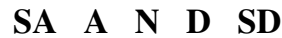

SA A N D SD

SA A N D SD

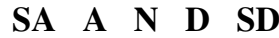

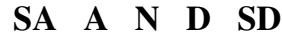

SA A N D SD

$\begin{array}{lllll}\text { SA } & A & \mathbf{N} & \mathbf{D} & \text { SD }\end{array}$

SA A N D SD

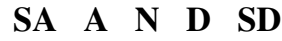

SA A N D $\quad$ SD

SA A N D SD 